\title{
Sensory Impact of Extended Maceration and Regulated Deficit Irrigation on Washington State Cabernet Sauvignon Wines
}

\author{
L. Federico Casassa, ${ }^{1,2}$ Richard C. Larsen, ${ }^{3}$ Christopher W. Beaver, ${ }^{1}$ \\ Maria S. Mireles, ${ }^{1}$ Markus Keller, ${ }^{4}$ William R. Riley, ${ }^{5}$ Russell Smithyman, ${ }^{5}$ \\ and James F. Harbertson ${ }^{1 *}$
}

\begin{abstract}
Irrigation practices such as regulated deficit irrigation (RDI) and winemaking practices such as extended maceration have been experimentally evaluated from a chemical perspective but their impacts on sensory composition and interactive effects merit scientific attention. This study evaluated the sensory impact of extended maceration applied to Cabernet Sauvignon grapes sourced from a vineyard subjected to four RDI treatments: replenishment of $100 \%, 70 \%$, and $25 \%$ of full-vine crop evapotranspiration $\left(\mathrm{ET}_{\mathrm{c}}\right.$ ) from fruit set until veraison followed by $100 \% \mathrm{ET}_{\mathrm{c}}$ until harvest (labeled $100 \% \mathrm{ET}_{\mathrm{c}}, 70 \% \mathrm{ET}_{\mathrm{c}}$, and $25 \% \mathrm{ET}_{\mathrm{c}}$, respectively) and $25 \% \mathrm{ET}_{\mathrm{c}}$ from fruit set to veraison followed by $100 \% \mathrm{ET}_{\mathrm{c}}$ from veraison to harvest (labeled $25 / 100 \% \mathrm{ET}_{\mathrm{c}}$ ). Each $\mathrm{RDI}$ treatment was replicated four times $(n=4)$ and made into wine, with two replicates designated as controls (10 day skin contact) and two as extended maceration (30 day skin contact). Wines were evaluated by descriptive analysis with a trained panel $(\mathrm{n}=$ 15) and chemical and sensory data were correlated using canonical correlation analysis. Wine-perceived saturation and purple component ratings were highest in $25 \% \mathrm{ET}_{\mathrm{c}}$ wines and were highly correlated with the concentration of flavonols, malvidin- and delphinidin-derivatives, and small polymeric pigments. Fruit-based aroma descriptors were highest in the $25 / 100 \% \mathrm{ET}_{\mathrm{c}}$ and $70 \% \mathrm{ET}_{\mathrm{c}}$ wines. Extended maceration increased perceived astringency and bitterness, which were in turn correlated with the concentration of flavan-3-ol and oligomeric proanthocyanidins. These results suggest that moderate RDI protocols such as $70 \% \mathrm{ET}_{\mathrm{c}}$ and $25 / 100 \% \mathrm{ET}_{\mathrm{c}}$ impact positively the fruity aroma component (black and red fruit), whereas extended maceration lowered fruity aromas, possibly due to the masking effect of the oxidized character perceived in these wines.
\end{abstract}

Key words: extended maceration, regulated deficit irrigation, wine aroma, oxidation, astringency, bitterness

In wines, observed variations in sensory attributes such as color (hue and saturation) and taste and mouthfeel properties (such as bitterness and astringency) are primarily the result of the composition and concentration of two phenolic classes, anthocyanins and proanthocyanidins (Lesschaeve and Noble 2005, Preys et al. 2006). Anthocyanins are pigments that modulate wine color directly due to their spectral properties and indirectly by participating in reactions such as copigmentation resulting in the typical hyperchromic shift (more color) and bathochromic shift (more purple color) observed in young

\footnotetext{
${ }^{1}$ School of Food Science, Washington State University, Irrigated Agriculture Research and Extension Center, 24106 N. Bunn Rd., Prosser, WA 99350; ${ }^{2}$ Wine Research Center, Estación Experimental Agropecuaria Mendoza, Instituto Nacional de Tecnología Agropecuaria, Luján de Cuyo, Mendoza, Argentina; ${ }^{3}$ Viticulture and Enology Program, and ${ }^{4}$ Department of Horticulture, Washington State University, IAREC, 24106 N. Bunn Rd., Prosser, WA 99350; and ${ }^{5}$ Ste. Michelle Wine Estates, 660 Frontier Rd., Prosser, WA 99350. *Corresponding author (email: jfharbertson@wsu.edu; tel: 509 786-9296; fax: 509 786-9370)

Acknowledgments: The authors are grateful to the panelist members from the WSU-Prosser community and to Snoqualmie, Canoe Ridge, and Columbia Crest wineries for their commitment to this study.

Manuscript submitted May 2013, revised Aug 2013, accepted Aug 2013

Copyright (C) 2013 by the American Society for Enology and Viticulture. All rights reserved.

doi: 10.5344/ajev.2013.13068
}

red wines (Boulton 2001). Isolated anthocyanins are tasteless or indistinctly flavored (Vidal et al. 2004). However, when anthocyanins react with proanthocyanidins during winemaking, polymeric pigments are formed and these in turn can modulate astringency (Weber et al. 2013).

Proanthocyanidins (also referred to as tannins) and, to a lesser extent, monomeric flavan-3-ols, display high affinity for proline-rich proteins found in the saliva of humans and other mammals (Mehansho et al. 1987, Poncet-Legrand et al. 2007). The tactile sensation of astringency arises from the formation of proanthocyanidin-protein complexes upon contact of the wine proanthocyanidins with the oral epithelium in a reaction driven by both hydrophobic interactions and hydrogen bonding (Baxter et al. 1997, Simon et al. 2003). Epicatechin-3-O-gallate and catechin can precipitate prolinerich proteins when the molar ratio of flavan-3-ols to protein exceeds 27 (Poncet-Legrand et al. 2006), which highlights the potential cooperative role of flavan-3-ols in astringency perception in red wine.

Management of the maceration period during red wine production is arguably the most common practice to achieve the selective diffusion of phenolics, aroma precursors, and free aroma compounds from the skins, seeds, and stems (when present). Extended maceration (EM) is a widely used winemaking technique based on extending the contact of the fermentation solids with the wine after fermentation is 
completed (Sacchi et al. 2005, Casassa et al. 2013a). This technique has been used to alter the mouthfeel of the wines, possibly by facilitating proanthocyanidin extraction and the formation of polymeric pigments (Harbertson et al. 2009, Casassa et al. 2013a). However, changes in mouthfeel induced by extended maceration may also arise from modifications in proanthocyanidin structure or size, resulting in a sensory impact beyond that of their concentration in solution.

In addition to its role in the extraction of anthocyanins and proanthocyanidins, contact of the must/wine with the fermentation solids is also needed to extract the precursors of aroma compounds that ultimately define red wine aroma. However, longer maceration time does not necessarily result in an enhancement of fruity aromas in the resulting wines (Harbertson et al. 2009, Casassa et al. 2013a) because the maceration time may have competing effects on the volatile composition depending on the rate of release from the tissues, formation of other compounds (such as acetaldehyde), and/or physical sorption or binding (Callejón et al. 2012).

Reports on the effect of regulated deficit irrigation (RDI) and other irrigation alternatives on the sensory profile of the wines are few and often conflicting. In a study of the sensory properties in Cabernet Sauvignon subjected to three drip irrigation treatments - minimal irrigation, standard irrigation (32 L water/vine/week), and double irrigation (64 L water/ vine/week) - descriptive analysis showed that vine water deficits led to wines with fruitier and less vegetal aromas and a reduced astringency, as compared with vines with high vine water status (Chapman et al. 2005). In an evaluation of the sensory attributes of Merlot wines produced from vines under different levels of water stress $(35,70,100$, and 35 to $70 \%$ of crop evapotranspiration; $\mathrm{ET}_{\mathrm{c}}$ ), results indicated that preveraison deficit at $35 \% \mathrm{ET}_{\mathrm{c}}$ increased fruity aromas and that preveraison deficit followed by $\mathrm{ET}_{\mathrm{c}}$ reposition of $70 \%$ increased the drying mouthfeel in the resulting wines (Ou et al. 2010). In both of these studies, chromatic properties and perceived color of wines were not examined.

The present study expands on a previous investigation that described the chemical features of wines produced from a combination of two contrasting skin contact treatments (control, 10-day skin contact; extended maceration (EM, 30day skin contact) applied to fruit produced under four RDI treatments $\left(100 \% \mathrm{ET}_{\mathrm{c}}, 70 \% \mathrm{ET}_{\mathrm{c}}, 25 / 100 \% \mathrm{ET}_{\mathrm{c}}\right.$, and $\left.25 \% \mathrm{ET}_{\mathrm{c}}\right)$ (Casassa et al. 2013b). The objectives of the present work were to generate a descriptive analysis of the wines with emphasis on color, aroma, and mouthfeel properties to understand the individual and combined sensory effect of skin contact time and RDI treatments and to elucidate relationships between the chemical and sensory compositions of the wines.

\section{Materials and Methods}

Experimental design. Own-rooted Vitis vinifera cv. Cabernet Sauvignon (clone 8) grown in the Cold Creek vineyard of Ste. Michelle Wine Estates, southeast of Mattawa, Washington State (lat. 46 $57^{\prime} \mathrm{N}$; long. $119^{\circ} 89^{\prime} \mathrm{W}$ ) was manually harvested on 12 Oct 2011 and processed at the Washington State University (WSU) research winery facility. The design consisted of a combination of four RDI treatments and two winemaking skin contact treatments. The current industry standard for RDI was used as a control to replenish $70 \%$ of full-vine crop evapotranspiration $\left(\mathrm{ET}_{\mathrm{c}}\right)$ through harvest $(70 \%$ $\mathrm{ET}_{\mathrm{c}}$ ). This standard was derived from a reference crop (grass) evapotranspiration $\left(\mathrm{ET}_{\mathrm{o}}\right.$ ) provided by the WSU AgWeatherNet station and a variable crop coefficient $\left(\mathrm{K}_{\mathrm{c}}\right)$ developed for fully irrigated Cabernet Sauvignon vines in eastern Washington. The remaining treatments were imposed to replenish $100 \%$ $\mathrm{ET}_{\mathrm{c}}$ and $25 \% \mathrm{ET}_{\mathrm{c}}$ from fruit set to harvest and 25\% $\mathrm{ET}_{\mathrm{c}}$ from fruit set to veraison followed by $100 \% \mathrm{ET}_{\mathrm{c}}$ from veraison to harvest $\left(25 / 100 \% \mathrm{ET}_{\mathrm{c}}\right)$. The field experiment was designed as a randomized complete block with four replicated blocks ( $\mathrm{n}=$ 4) and the RDI treatments randomly applied ( $\geq 6$ rows each) within each block. The two skin contact treatments were applied in duplicate using two of the four field replicates of each RDI treatment - control wines, with a 10-day skin contact period, and extended maceration wines (EM), with a 30-day skin contact period - for a total of 16 wines. More details on the vineyard site, winemaking protocol, and chemical analysis of fruit and wines are described in Casassa et al. (2013b). Monomeric anthocyanins and flavonols were determined by HPLC-DAD-MS. Protein precipitable tannins, iron-reactive phenolics, large polymeric pigments, and small polymeric pigments were measured as in Harbertson et al. (2003).

Descriptive analysis. Descriptive analysis of the wines was conducted after three months of bottle aging as described by Lawless and Heymann (2010). A prescreening of the wines by four experienced wine tasters ensured that the wines were different enough to justify a descriptive analysis and also that they were free of sulfur-like or other off-odors. A trained panel was convened $(n=17,10$ females and 7 males, ages ranging from 24 to 63 years). No information about the nature of the study was provided in order to reduce bias, and the WSU Institutional Review Board for human subject participation approved the project. Panelists were screened for both potential color deficiencies and bitterness sensitivity (also known as PROP status) as detailed previously (Casassa et al. 2013a). The results of these tests indicated that none of the panelists had color deficiencies and that the panel was composed of $25 \%$ nontasters, $13 \%$ medium tasters, and $62 \%$ supertasters (Pickering et al. 2004).

Panel training and evaluation. Panelists were trained during seven sessions, each lasting one hour with an additional session for review of standards and self-calibration. After terminology development, four color components (purple, red, brown, and saturation), three aroma attributes (red fruit, black fruit, and oxidized character), and two mouthfeel attributes (astringency and bitterness) were retained upon general consensus. Astringency was defined as the puckering or lack of lubrication sensation around the gums immediately after expectoration of the wine (Gawel et al. 2000). During the training and evaluation sessions, a $15 \mathrm{~cm}$ unstructured line scale was used, labeled with terms low and high at the $1 \mathrm{~cm}$ and $14 \mathrm{~cm}$ mark from the left side of the scale, respectively. Except for the purple, red, and brown color components, the standards were prepared at low, medium, and high levels 
(Table 1), representing anchors located at $1 \mathrm{~cm}, 7.5 \mathrm{~cm}$, and $14 \mathrm{~cm}$, respectively, from the left end of the unstructured scale. An example of each standard at the three intensity levels was initially presented to the panelists, but the final intensity of each attribute was modified upon panelist feedback (Table 1).

The experimental wines were evaluated during five formal evaluation sessions. Panelists tasted six or seven wines per evaluation session. Wines and their replicates were presented monadically and evaluated twice following a randomized Williams Latin Square block design for control of possible carryover effects, yielding a final count of 480 observations (16 wines $\times 15$ panelists $\times 2$ replicates) for each attribute. Panelists assessed the wines in individual booths $\left(20 \pm 2{ }^{\circ} \mathrm{C}\right)$, lighted with Lumichrome full spectrum lamps $(6,500 \mathrm{~K})$ in the WSU Sensory Laboratory. Aliquots of wine $(30 \mathrm{~mL})$ at room temperature were poured into wineglasses coded with three-digit random numbers and covered with aluminum lids to trap volatiles. To reduce buildup and carryover effects, bitterness was evaluated prior to astringency. Prior to astringency evaluation, panelists were instructed to chew one cracker, rinse with deionized water, and wait at least 4 min between samples, during which they assessed the color components of another sample. Results were collected on ballots and responses (in cm) were decoded manually. After the formal evaluation sessions, panel performance was monitored by assessing the correlation of each panelist with the panel mean and by their contribution to the panelist $\times$ wine interaction for each attribute. Based on these analyses, it was decided to remove data from two panelists (final $\mathrm{n}=15$ ).

Materials and standards. 6- $n$-Propylthiouracil (PROP), caffeine (food grade), and acetaldehyde ( $>99 \%$ purity) were obtained from Sigma-Aldrich (St. Louis, MO). For preparation of reference standards (Table 1), raspberry jam and blackberry jam (Smucker's, Orrville, $\mathrm{OH}$ ) and blueberry/ blackcurrant preserve (Mackays, Arbroath, Scotland) were obtained through local grocery stores. Freeze-dried powdered strawberries were obtained from WSU Prosser. Reference standards for aroma were prepared using a base wine (Paisano Red, Carlo Rossi Vineyards, Modesto, CA) previously stripped of most aroma compounds under reduced pressure $\left(30^{\circ} \mathrm{C} \times 45 \mathrm{~min} / \mathrm{L}\right)$ using a Büchi Syncore Polyvap (Flawil, Switzerland). Astringency standards were prepared using a 2010 Cabernet Sauvignon wine and a 2010 Merlot wine produced at the WSU winery. Bitterness and color standards were prepared using as a base wine a 2010 Merlot produced at the WSU winery. The color components and saturation standards were obtained by varying the $\mathrm{pH}$ and/or by addition of acetaldehyde, $\mathrm{H}_{2} \mathrm{O}_{2}$, and $\mathrm{SO}_{2}$, with specifications reported as CIELab units (Table 1). Unsalted crackers (Great Value, Bentonville, AR) and deionized (18.2 $\mathrm{M} \Omega \cdot \mathrm{cm}$ resistivity) water (Milli-Q, EMD Millipore, Billerica, MA) were provided for palate cleansing. To avoid perceptual bias due to color, tulipshaped cobalt black glasses (Libbey, Toledo, OH) were used for evaluation of aroma and mouthfeel attributes. Clear ISO wineglasses (ISO 1977) were used only for color evaluations.

Table 1 Ingredients, specifications, and lexicon of sensory analysis standards used during the training and formal evaluation sessions.

\begin{tabular}{|c|c|c|c|}
\hline \multirow[b]{2}{*}{ Reference standard } & \multicolumn{3}{|c|}{ Level } \\
\hline & Low & Medium & High \\
\hline \multicolumn{4}{|l|}{ Aroma $^{a}$} \\
\hline Red fruit character & $\begin{array}{c}1.1 \mathrm{~g} \text { raspberry jam and } \\
40 \mathrm{mg} \text { freeze-dried powdered } \\
\text { strawberries }\end{array}$ & $\begin{array}{c}4.5 \mathrm{~g} \text { raspberry jam and } \\
150 \mathrm{mg} \text { freeze-dried powdered } \\
\text { strawberries }\end{array}$ & $\begin{array}{c}7.5 \mathrm{~g} \text { raspberry jam and } \\
250 \mathrm{mg} \text { freeze-dried powdered } \\
\text { strawberries }\end{array}$ \\
\hline Black fruit character & $\begin{array}{c}3 \mathrm{~g} \text { each blackberry jam and } \\
\text { blueberry/ } \\
\text { blackcurrant preserve }\end{array}$ & $\begin{array}{c}4.5 \mathrm{~g} \text { each blackberry jam and } \\
\text { blueberry/ } \\
\text { blackcurrant preserve }\end{array}$ & $\begin{array}{c}9 \mathrm{~g} \text { each blackberry jam } \\
\text { and blueberry/ } \\
\text { blackcurrant preserve }\end{array}$ \\
\hline Oxidized character & $56 \mu \mathrm{L}$ acetaldehyde & $150 \mu \mathrm{L}$ acetaldehyde & $300 \mu \mathrm{L}$ acetaldehyde \\
\hline \multicolumn{4}{|l|}{ Color $^{b}$} \\
\hline Purple component & NA & NA & $\begin{array}{c}\mathrm{L}^{*}=28.2 ; \mathrm{C}^{*}=64.6 \\
\mathrm{H}^{*}=25.1 ; \mathrm{a}^{*}=58.5 \\
\mathrm{~b}^{*}=27.4\end{array}$ \\
\hline Red component & NA & NA & $\begin{array}{c}\mathrm{L}^{*}=35.4 ; \mathrm{C}^{*}=58.4 \\
\mathrm{H}^{*}=22.0 ; \mathrm{a}^{*}=54.1 \\
\mathrm{~b}^{*}=21.9\end{array}$ \\
\hline Brown component & NA & NA & $\begin{array}{c}\mathrm{L}^{*}=61.3 ; \mathrm{C}^{*}=40.6 \\
\mathrm{H}^{*}=42.4 ; \mathrm{a}^{*}=29.9 \\
\mathrm{~b}^{*}=27.4\end{array}$ \\
\hline Saturation & $C^{*}=22.9$ & $C^{*}=50.5$ & $C^{*}=64.6$ \\
\hline \multicolumn{4}{|l|}{ Taste/mouthfeel } \\
\hline Bitterness $^{c}$ & No addition & 75 mg caffeine & 200 mg caffeine \\
\hline Astringency ${ }^{d}$ & 188 mg/L PPT & 649 mg/L PPT & 1583 mg/L PPT \\
\hline
\end{tabular}

${ }^{a}$ Aroma standards prepared at three levels and dissolved in $750 \mathrm{~mL}$ base wine (Paisano Red) stripped of aroma compounds under reduced pressure $\left(30^{\circ} \mathrm{C} \times 45 \mathrm{~min}\right)$.

'Base wine: 2010 Merlot. NA: not applicable. CIELab values: $L^{*}$ : lightness; $C^{*}$ : saturation or chroma; $H^{*}$ : hue; $a^{*}$ : red component; $b^{*}$ : blue component.

'Base wine: 2010 Merlot.

${ }^{\mathrm{d} B a s e}$ wine: 2010 Merlot (188 mg/L protein-precipitable tannins [PPT]); 56/44 blend 2010 Merlot and 2010 Cabernet Sauvignon (649 mg/L PPT); 2010 Cabernet Sauvignon (1583 mg/L PPT). 
Data analysis. The significance of effect of RDI, skin contact time, and their interaction on sensory composition was analyzed by a two-way ANOVA with separation of the means accomplished using Fisher's LSD and the significance value established as $p<0.05$ using XLSTAT ver. 2011 (Addinsoft, Paris, France). Principal component analysis (PCA) using the correlation matrix with no rotation was applied on the wine sensory data, including the replicates, using $\mathrm{R}$ software (R Foundation for Statistical Computing, Vienna, Austria). Confidence ellipses indicating 95\% confidence intervals were based on the multivariate distribution of the Hotelling's test for $p<0.05$ and were constructed using SensoMineR panellipse function on R (Husson et al. 2005). Two-way canonical correlation analysis with clustered image maps to relate sensory and chemical data was obtained using the mix0mics package of R software (González et al. 2012).

\section{Results and Discussion}

Chemical composition of wines. A detailed discussion of the chemical composition of the wines of this study has been reported previously (Casassa et al. 2013b). Therefore, only a brief summary is given here of the chromatic composition, anthocyanins, polymeric pigments, iron-reactive phenolics and flavonols, and proanthocyanidin composition with the reported proportion of skin- and seed-derived tannins for the individual Cabernet Sauvignon wines $(\mathrm{n}=16)$. In terms of chromatic differences, the control wines had generally lower lightness values $\left(\mathrm{L}^{*}\right)$ than their EM counterparts (Table 2). With regard to the effect of RDI, the $25 \% \mathrm{ET}_{\mathrm{c}}$ treatment produced wines with overall higher saturation $\left(\mathrm{C}^{*}\right)$, hue $\left(\mathrm{H}^{*}\right)$, and yellow component $\left(\mathrm{b}^{*}\right)$ values than the other RDI treatments. In terms of phenolic parameters, anthocyanins were generally higher in control wines (with the sole exception of the $25 / 100 \% \mathrm{ET}_{\mathrm{c}}$ control and EM treatments), whereas ironreactive phenolics were consistently higher in the EM wines (Table 3). The RDI treatment applied at $25 \% \mathrm{ET}_{\mathrm{c}}$ resulted in an increase in wine anthocyanins and small polymeric pigments. Protein-precipitable tannins, flavan-3-ols, and oligomeric proanthocyanidins were generally higher in EM wines (Table 4). The proportion of skin- and seed-derived tannins affected by the RDI and skin contact treatments showed an unclear trend in the one-way ANOVA, likely due to the rather small sample size and thus insufficient statistical power. However, in an earlier study, a two-way ANOVA captured a significant effect of the skin contact treatment with an overall proportion of $55 \%$ of seed-derived tannins in control wines versus $73 \%$ of seed-derived tannins in EM wines (Casassa et al. 2013b). Once again, the effect of the RDI treatment on protein-precipitable tannins and proanthocyanidin composition was less evident than the effect of the skin contact treatment.

Descriptive analysis. The main goal of this study was to assess the sensory impact of extended maceration applied to Cabernet Sauvignon grapes produced using four different RDI protocols. To that end, a descriptive analysis with a trained panel was conducted to determine specific sensory effects of both the maceration and the RDI treatments. Potential synergistic or antagonistic sensory effects of extended maceration on the fruit of the different RDI treatments were also explored. A fixed-effect two-way ANOVA with interaction was performed on the sensory data (Table 5). The RDI treatment influenced the sensory profile of the wines, with particular impact on color, taste (bitterness), and mouthfeel (astringency) components. However, the effect of the maceration treatment prevailed in all the sensory attributes, a trend also previously reported for the wine chemical composition.

A significant RDI treatment $\times$ winemaking interaction was observed for the purple and red color components, black fruit aroma, and bitterness. The significance of the interaction for these attributes called for reevaluation of the treatment effects and first-order interactions by one-way ANOVA (Table 6). The purple component was more (negatively) affected in

Table 2 One-way ANOVA of CIELab color parameters of Cabernet Sauvignon wines subjected to four different regulated deficit irrigation regimes $(\mathrm{RDI})$ and two skin contact time treatments $(\mathrm{EM})$ at day 250 postcrushing.

\begin{tabular}{|c|c|c|c|c|c|}
\hline RDI/skin contact ${ }^{a}$ & $L^{*}$ & $\mathrm{C}^{*}$ & $\mathrm{H}^{*}$ & $a^{*}$ & $\mathbf{b}^{*}$ \\
\hline \multicolumn{6}{|l|}{$100 \% \mathrm{ET}_{\mathrm{c}}$} \\
\hline Control & $44.5 \mathrm{cde}^{\mathrm{b}}$ & $53.5 \mathrm{a}$ & $10.7 \mathrm{a}$ & $52.8 \mathrm{abc}$ & $10.0 \mathrm{a}$ \\
\hline EM & $49.8 \mathrm{f}$ & $50.6 \mathrm{a}$ & $11.4 \mathrm{a}$ & $49.6 \mathrm{a}$ & $10.0 \mathrm{a}$ \\
\hline \multicolumn{6}{|l|}{$70 \% \mathrm{ET}_{\mathrm{c}}$} \\
\hline Control & $40.8 \mathrm{bc}$ & $55.4 a b$ & $11.9 \mathrm{a}$ & $54.2 \mathrm{bc}$ & $11.4 \mathrm{a}$ \\
\hline EM & 49.5 ef & $50.6 \mathrm{a}$ & $12.2 a b$ & $49.5 \mathrm{a}$ & $10.7 \mathrm{a}$ \\
\hline \multicolumn{6}{|l|}{$25 / 100 \% \mathrm{ET}_{\mathrm{c}}$} \\
\hline Control & $41.9 \mathrm{~cd}$ & $55.2 \mathrm{ab}$ & $10.9 \mathrm{a}$ & $54.2 \mathrm{bc}$ & $10.5 \mathrm{a}$ \\
\hline EM & 46.7 ef & $52.9 \mathrm{a}$ & $11.7 \mathrm{a}$ & $51.8 \mathrm{ab}$ & $10.8 \mathrm{a}$ \\
\hline \multicolumn{6}{|l|}{$25 \% \mathrm{ET}_{\mathrm{c}}$} \\
\hline Control & $34.2 \mathrm{a}$ & $59.1 \mathrm{~b}$ & $15.6 \mathrm{bc}$ & $56.8 \mathrm{c}$ & $15.9 \mathrm{~b}$ \\
\hline EM & $36.8 a b$ & $58.9 \mathrm{~b}$ & $16.3 \mathrm{c}$ & $56.5 \mathrm{c}$ & $16.5 \mathrm{~b}$ \\
\hline$p$ value & 0.001 & 0.024 & 0.034 & 0.029 & 0.025 \\
\hline
\end{tabular}

aRDI treatments: $100 \% \mathrm{ET}_{c}, 70 \% \mathrm{ET}_{c}$, and $25 \% \mathrm{ET}_{\text {c }}$ represent replenishment of $100 \%, 70 \%$, and $25 \%$, respectively, of full-vine $\mathrm{ET}$ from fruit set through harvest; $25 / 100 \% \mathrm{ET}_{\mathrm{c}}$ represents $25 \% \mathrm{ET}_{\mathrm{c}}$ from fruit set to veraison followed by $100 \% \mathrm{ET}_{\mathrm{c}}$ from veraison to harvest. Skin contact treatments: control (10 days skin contact); EM: extended maceration (30 days skin contact).

bWithin a column, values followed by the same letter are not significantly different according to Fisher's LSD test at $p<0.05$. 
the $70 \% \mathrm{ET}_{\mathrm{c}}$ treatment than in the other RDI treatments upon application of EM. Additionally, a two-way ANOVA applied to the previously reported anthocyanin content of the wines at day 250 (coincident with the sensory analysis) revealed a small yet significant RDI $\times$ winemaking effect for anthocyanins ( $p=0.044)$ (Casassa et al. 2013b). This effect followed the same direction observed in the visual purple component, which explains the observed sensory interaction.

There was also a significant RDI $\times$ winemaking interaction for the black fruit aroma component (Table 5). A one-way ANOVA indicated that the perception of the black fruit aroma decreased proportionally more in the $25 \% \mathrm{ET}_{\mathrm{c}}$ treatment than in the other treatments upon application of EM, although the reason for this decrease is unknown. However, extended maceration in general decreased the perception of the black fruit aroma (Table 6). Recently, Callejón et al. (2012) reported that in microfermentations $(1 \mathrm{~L})$ of Cabernet Sauvignon wines, some norisoprenoids such as $\beta$-damascenone could be selectively bound by the skins and other fermentation solids during prolonged maceration, thereby decreasing their volatility. In turn, $\beta$-damascenone has been shown to synergistically increase the perception of the black fruit note (Pineau et al. 2007), which may explain the lower ratings of the black fruit attribute in extended maceration wines. Lastly, bitterness was

Table 3 One-way ANOVA of selected phenolic parameters of Cabernet Sauvignon wines subjected to four different regulated deficit irrigation regimes $(\mathrm{RDI})$ and two skin contact time treatments at day 250 postcrushing.

\begin{tabular}{|c|c|c|c|c|c|}
\hline $\begin{array}{l}\text { RDI/ } \\
\text { skin contact }^{a}\end{array}$ & $\begin{array}{c}\text { Anthocyanins } \\
\text { (mg/L malvidin- } \\
\text { 3-glucoside) }\end{array}$ & $\begin{array}{c}\text { SPP } \\
(A U 520 \mathrm{~nm})\end{array}$ & $\begin{array}{c}\text { LPP } \\
(\mathrm{AU} 520 \mathrm{~nm})\end{array}$ & $\begin{array}{l}\text { Iron-reactive } \\
\text { phenolics } \\
\text { (mg/L CE }{ }^{\mathrm{b}} \text { ) }\end{array}$ & $\begin{array}{c}\text { Flavonols } \\
\text { (mg/L quercetin- } \\
\text { 3-glucoside) }\end{array}$ \\
\hline \multicolumn{6}{|l|}{$100 \% \mathrm{ET}_{\mathrm{c}}$} \\
\hline Control & $342 b c^{c}$ & $1.8 a b$ & $1.0 \mathrm{ab}$ & $1857 \mathrm{abc}$ & $98 a b$ \\
\hline EM & $271 \mathrm{a}$ & $1.5 \mathrm{a}$ & $0.8 \mathrm{a}$ & $2384 d$ & $84 \mathrm{a}$ \\
\hline \multicolumn{6}{|l|}{$70 \% \mathrm{ET}_{c}$} \\
\hline Control & $392 \mathrm{c}$ & $2.1 \mathrm{bc}$ & $1.3 \mathrm{ab}$ & $1765 b$ & $109 a b c$ \\
\hline EM & $282 a b$ & $1.8 \mathrm{ab}$ & $0.8 \mathrm{a}$ & $2423 d$ & 84 a \\
\hline \multicolumn{6}{|l|}{$25 / 100 \% \mathrm{ET}_{\mathrm{c}}$} \\
\hline Control & $352 \mathrm{c}$ & $2.1 \mathrm{bc}$ & $0.7 \mathrm{a}$ & 1665 a & $107 \mathrm{abc}$ \\
\hline EM & $325 a b c$ & $1.9 \mathrm{~b}$ & $0.8 \mathrm{a}$ & $2239 \mathrm{bcd}$ & $101 a b$ \\
\hline \multicolumn{6}{|l|}{$25 \% \mathrm{ET}_{\mathrm{c}}$} \\
\hline Control & $485 \mathrm{~d}$ & $2.8 d$ & $1.3 \mathrm{ab}$ & $1767 a b$ & $139 \mathrm{c}$ \\
\hline EM & $377 c$ & $2.4 \mathrm{~cd}$ & $1.5 \mathrm{~b}$ & $2642 d$ & $128 \mathrm{bc}$ \\
\hline$p$ value & 0.0010 & 0.0017 & 0.1082 & 0.0161 & 0.0298 \\
\hline
\end{tabular}

aRDI treatments: $100 \% \mathrm{ET}_{\mathrm{c}}, 70 \% \mathrm{ET}_{\mathrm{c}}$, and $25 \% \mathrm{ET}_{\mathrm{c}}$ represent replenishment of $100 \%, 70 \%$, and $25 \%$, respectively, of full-vine $\mathrm{ET}_{\mathrm{c}}$ from fruit set through harvest; $25 / 100 \% \mathrm{ET}_{\mathrm{c}}$ represents $25 \% \mathrm{ET}_{\mathrm{c}}$ from fruit set to veraison followed by $100 \% \mathrm{ET}_{\mathrm{c}}$ from veraison to harvest. Skin contact treatments: control (10 days skin contact); EM: extended maceration (30 days skin contact).

${ }^{b}$ Catechin equivalents.

'Within a column, values followed by the same letter are not significantly different according to Fisher's LSD test at $p<0.05$.

Table 4 One-way ANOVA of protein-precipitable tannins (PPT), proanthocyanidin (PA) composition, and proportion of skin- and seed-derived tannins of Cabernet Sauvignon wines subjected to four different regulated deficit irrigation regimes (RDI) and two skin contact time treatments at day 250 postcrushing.

\begin{tabular}{|c|c|c|c|c|c|c|}
\hline $\begin{array}{l}\text { RDI/ } \\
\text { skin contact }^{\mathrm{a}}\end{array}$ & $\begin{array}{c}\text { PPT } \\
\left(\mathrm{mg} / \mathrm{L} \mathrm{CE}^{\mathrm{b}}\right)\end{array}$ & $\begin{array}{c}\text { Flavan-3-ols } \\
\text { (mg/L CE) }\end{array}$ & $\begin{array}{c}\text { Oligomeric PA } \\
\text { (mg/L CE) }\end{array}$ & $\begin{array}{c}\text { Polymeric PA } \\
\text { (mg/L CE) }\end{array}$ & $\begin{array}{c}\text { Skin-derived } \\
\text { tannins (\%) }\end{array}$ & $\begin{array}{c}\text { Seed-derived } \\
\text { tannins (\%) }\end{array}$ \\
\hline \multicolumn{7}{|l|}{$100 \% \mathrm{ET}_{\mathrm{c}}$} \\
\hline Control & $732 a b c^{c}$ & $133 a$ & $366 \mathrm{a}$ & $491 \mathrm{a}$ & $29 a b c$ & $71 \mathrm{bcd}$ \\
\hline EM & $878 \mathrm{~cd}$ & $285 \mathrm{bc}$ & $989 \mathrm{c}$ & $688 \mathrm{abc}$ & $23 a b$ & $76 \mathrm{~cd}$ \\
\hline \multicolumn{7}{|l|}{$70 \% \mathrm{ET}_{\mathrm{c}}$} \\
\hline Control & $703 a b c$ & 279 bc & $578 \mathrm{~b}$ & $437 \mathrm{a}$ & $59 d$ & $41 \mathrm{a}$ \\
\hline $\mathrm{EM}$ & 949 de & $372 c$ & $1077 \mathrm{c}$ & $1003 \mathrm{c}$ & $21 \mathrm{a}$ & $79 \mathrm{~d}$ \\
\hline \multicolumn{7}{|l|}{$25 / 100 \% \mathrm{ET}_{\mathrm{c}}$} \\
\hline Control & $568 \mathrm{a}$ & $232 b$ & $535 a b$ & $592 a b$ & $44 \mathrm{bcd}$ & $56 a b c$ \\
\hline EM & $768 \mathrm{bc}$ & $341 \mathrm{c}$ & $893 \mathrm{c}$ & $615 a b$ & $31 \mathrm{abc}$ & $69 \mathrm{bcd}$ \\
\hline \multicolumn{7}{|l|}{$25 \% \mathrm{ET}_{\mathrm{c}}$} \\
\hline Control & $613 a b$ & 286 bc & $424 a b$ & $385 a$ & $46 \mathrm{~cd}$ & $54 a b$ \\
\hline EM & 1067 e & $385 d$ & $974 \mathrm{c}$ & $877 b c$ & 37 abcd & 63 abcd \\
\hline$p$ value & 0.0002 & 0.0012 & $<0.0001$ & 0.0165 & 0.0119 & 0.0119 \\
\hline
\end{tabular}

${ }^{a} \mathrm{RDI}$ treatments: $100 \% \mathrm{ET}_{\mathrm{c}}, 70 \% \mathrm{ET}_{\mathrm{c}}$, and $25 \% \mathrm{ET}_{\mathrm{c}}$ represent replenishment of $100 \%, 70 \%$, and $25 \%$, respectively, of full-vine $\mathrm{ET}_{\mathrm{c}}$ from fruit set through harvest; $25 / 100 \% \mathrm{ET}_{\mathrm{c}}$ represents $25 \% \mathrm{ET}_{\mathrm{c}}$ from fruit set to veraison followed by $100 \% \mathrm{ET}_{\mathrm{c}}$ from veraison to harvest. Skin contact treatments: control (10 days skin contact); EM: extended maceration (30 days skin contact).

${ }^{\mathrm{b}}$ Catechin equivalents.

'Within a column, values followed by the same letter are not significantly different according to Fisher's LSD test at $p<0.05$. 
also comparatively more accentuated in the $70 \% \mathrm{ET}_{\mathrm{c}}$ treatment upon EM than in the wines of the other RDI treatments.

Principal component analysis. To further explore the comparative influence of both the maceration and the RDI treatments on the sensory profile of the wines, the full data set was submitted to principal component analysis (PCA), including the wine replicates and the repeated measures performed during the formal sensory sessions. The PCA biplot and confidence ellipses were constructed with $95 \%$ certainty according to the Hotteling's test (Husson et al. 2005), which provides significance testing. Only the first two principal components with eigenvalues greater than or equal to one were retained (Figure 1). The PCA plot showed a bidimensional model that explained $94 \%$ of the observed variability. Dimension 1, which explained $\sim 77 \%$ of the variability, was a function of the maceration treatment, which suggests a comparatively higher impact of the EM treatment over the RDI treatments on the sensory profile of the wines. Irrespective of the RDI treatment, control wines clustered in the negative region of dimension 1, whereas EM wines grouped on the positive region of dimension 1 (Figure A). There were strong correlations between EM wines and the red and brown color components, oxidized character, astringency and bitterness, all located in the positive side of dimension 1 (Figure 1B).

Table 5 Main effects and interaction of descriptive sensory attributes $(n=15)$ of Cabernet Sauvignon wines subjected to four different regulated deficit irrigation regimes (RDI) and two skin contact (SC) time treatments.

\begin{tabular}{|c|c|c|c|c|c|c|c|c|c|c|}
\hline \multirow[b]{2}{*}{$\begin{array}{l}\text { ANOVA } \\
\text { parameter }^{a}\end{array}$} & \multirow[b]{2}{*}{ df } & \multicolumn{4}{|c|}{ Color components } & \multicolumn{3}{|c|}{ Aroma components } & \multicolumn{2}{|c|}{ Taste/mouthfeel } \\
\hline & & Purple & Red & Brown & Saturation & Red fruit & Black fruit & $\begin{array}{c}\text { Oxidized } \\
\text { character }\end{array}$ & Bitterness & Astringency \\
\hline RDI & 3 & & & & & & & & & \\
\hline $100 \% \mathrm{ET}_{\mathrm{c}}$ & & $10.5 a^{b}$ & $7.2 \mathrm{~b}$ & $1.2 \mathrm{a}$ & $10.1 \mathrm{a}$ & $4.5 \mathrm{a}$ & $6.4 \mathrm{a}$ & $1.9 \mathrm{a}$ & $6.9 \mathrm{a}$ & $10.6 \mathrm{~b}$ \\
\hline $70 \% \mathrm{ET}_{\mathrm{c}}$ & & $10.9 \mathrm{~b}$ & $6.9 \mathrm{a}$ & $1.2 \mathrm{a}$ & $11.1 \mathrm{~b}$ & $4.7 \mathrm{a}$ & $6.9 \mathrm{a}$ & $2.0 \mathrm{ab}$ & $7.5 \mathrm{~b}$ & $10.5 \mathrm{~b}$ \\
\hline $25 / 100 \% \mathrm{ET}_{\mathrm{c}}$ & & $11.4 \mathrm{c}$ & $6.6 \mathrm{a}$ & $1.1 \mathrm{a}$ & $11.5 \mathrm{c}$ & $4.8 \mathrm{a}$ & $7.5 \mathrm{~b}$ & $2.0 \mathrm{a}$ & $7.3 a b$ & $10.2 \mathrm{a}$ \\
\hline $25 \% \mathrm{ET}_{\mathrm{c}}$ & & $12.5 \mathrm{~d}$ & $6.7 \mathrm{a}$ & $1.1 \mathrm{a}$ & $13.1 \mathrm{~d}$ & $4.9 \mathrm{a}$ & $6.6 \mathrm{a}$ & $2.3 b$ & $7.9 \mathrm{c}$ & $11.4 \mathrm{c}$ \\
\hline$p$ value & & $<0.0001$ & 0.004 & 0.461 & $<0.0001$ & 0.371 & 0.001 & 0.111 & $<0.0001$ & $<0.0001$ \\
\hline Skin contact (SC) & 1 & & & & & & & & & \\
\hline Control & & $12.1 \mathrm{~b}$ & $6.1 \mathrm{a}$ & $0.9 \mathrm{a}$ & $11.9 \mathrm{~b}$ & $5.4 \mathrm{~b}$ & $7.6 \mathrm{~b}$ & $1.0 \mathrm{a}$ & $6.6 \mathrm{a}$ & $9.5 \mathrm{a}$ \\
\hline EM & & $10.6 \mathrm{a}$ & $7.6 \mathrm{~b}$ & $1.4 \mathrm{~b}$ & $11.0 \mathrm{a}$ & $4.0 \mathrm{a}$ & $6.0 \mathrm{a}$ & $3.1 \mathrm{~b}$ & $8.3 \mathrm{~b}$ & $11.8 \mathrm{~b}$ \\
\hline$p$ value & & $<0.0001$ & $<0.0001$ & $<0.0001$ & $<0.0001$ & $<0.0001$ & $<0.0001$ & $<0.0001$ & $<0.0001$ & $<0.0001$ \\
\hline RDI $\times$ SC & 3 & & & & & & & & & \\
\hline$p$ value & & $<0.0001$ & $<0.0001$ & 0.179 & 0.161 & 0.887 & $<0.0001$ & 0.256 & 0.006 & 0.232 \\
\hline
\end{tabular}

anDI treatments: $100 \% \mathrm{ET}_{c}, 70 \% \mathrm{ET}_{c}$, and $25 \% \mathrm{ET}_{\mathrm{c}}$ represent replenishment of $100 \%, 70 \%$, and $25 \%$, respectively, of full-vine $\mathrm{ET}_{\mathrm{c}}$ from fruit set through harvest; $25 / 100 \% \mathrm{ET}_{\mathrm{c}}$ represents $25 \% \mathrm{ET}_{\mathrm{c}}$ from fruit set to veraison followed by $100 \% \mathrm{ET}_{\mathrm{c}}$ from veraison to harvest. $\mathrm{SC}$ treatments: control (10 days skin contact); EM: extended maceration (30 days skin contact).

bWithin a column, values followed by the same letter are not significantly different according to Fisher's LSD test at $p<0.05$. Evaluations made along a $15 \mathrm{~cm}$ unstructured line scale.

Table 6 One-way ANOVA of descriptive sensory attributes $(n=15)$ of Cabernet Sauvignon wines subjected to four different regulated deficit irrigation regimes (RDI) and two skin contact (SC) time treatments.

\begin{tabular}{|c|c|c|c|c|c|c|c|c|c|}
\hline \multirow[b]{2}{*}{$\begin{array}{l}\text { RDI/ } \\
\text { Skin contact }{ }^{a}\end{array}$} & \multicolumn{4}{|c|}{ Color component } & \multicolumn{3}{|c|}{ Aroma components } & \multicolumn{2}{|c|}{ Taste/mouthfeel } \\
\hline & Purple & Red & Brown & Saturation & Red fruit & Black fruit & $\begin{array}{l}\text { Oxidized } \\
\text { character }\end{array}$ & Bitterness & Astringency \\
\hline \multicolumn{10}{|l|}{$100 \% \mathrm{ET}_{\mathrm{c}}$} \\
\hline Control & $11.1 b^{b}$ & $7.0 \mathrm{c}$ & $1.0 \mathrm{a}$ & $10.5 \mathrm{~b}$ & $5.3 \mathrm{~b}$ & $6.6 \mathrm{~cd}$ & $0.9 \mathrm{a}$ & $6.2 \mathrm{a}$ & $19.6 \mathrm{~b}$ \\
\hline EM & $9.9 \mathrm{a}$ & $7.4 \mathrm{~cd}$ & $1.4 \mathrm{~b}$ & $9.7 \mathrm{a}$ & $3.8 \mathrm{a}$ & $6.2 \mathrm{bc}$ & $2.9 \mathrm{~b}$ & $7.5 \mathrm{bc}$ & $111.6 \mathrm{de}$ \\
\hline \multicolumn{10}{|l|}{$70 \% \mathrm{ET}_{\mathrm{c}}$} \\
\hline Control & $12.1 \mathrm{c}$ & $6.0 \mathrm{~b}$ & $0.8 \mathrm{a}$ & $11.7 \mathrm{~d}$ & $5.3 \mathrm{~b}$ & $7.8 \mathrm{e}$ & $1.0 \mathrm{a}$ & $6.3 \mathrm{a}$ & $9.3 a b$ \\
\hline EM & $9.8 \mathrm{a}$ & $7.7 \mathrm{de}$ & $1.6 \mathrm{~b}$ & $10.5 \mathrm{~b}$ & $4.1 \mathrm{a}$ & $5.8 a b$ & $3.0 \mathrm{~b}$ & $8.8 \mathrm{~d}$ & $11.8 \mathrm{e}$ \\
\hline \multicolumn{10}{|l|}{$25 / 100 \% \mathrm{ET}_{\mathrm{c}}$} \\
\hline Control & $12.0 \mathrm{c}$ & $6.2 \mathrm{~b}$ & $0.9 \mathrm{a}$ & $11.8 \mathrm{~d}$ & $5.5 \mathrm{~b}$ & $8.0 \mathrm{e}$ & $1.1 \mathrm{a}$ & $6.6 \mathrm{a}$ & $8.9 \mathrm{a}$ \\
\hline EM & $10.8 \mathrm{~b}$ & $7.0 \mathrm{c}$ & $1.4 \mathrm{~b}$ & $11.2 \mathrm{c}$ & $4.2 \mathrm{a}$ & $7.0 \mathrm{~d}$ & $2.9 \mathrm{~b}$ & $8.0 \mathrm{c}$ & $11.4 \mathrm{~d}$ \\
\hline \multicolumn{10}{|l|}{$25 \% \mathrm{ET}_{\mathrm{c}}$} \\
\hline Control & $13.2 \mathrm{~b}$ & $5.2 \mathrm{a}$ & $0.8 \mathrm{a}$ & $13.5 \mathrm{f}$ & $5.6 \mathrm{~b}$ & $8.0 \mathrm{e}$ & $1.1 \mathrm{a}$ & $7.2 \mathrm{~b}$ & $10.1 \mathrm{c}$ \\
\hline EM & $11.8 \mathrm{c}$ & $8.1 \mathrm{e}$ & $1.4 \mathrm{~b}$ & $12.6 \mathrm{e}$ & $4.1 \mathrm{a}$ & $5.2 \mathrm{a}$ & $3.4 \mathrm{c}$ & $8.7 \mathrm{c}$ & $12.6 \mathrm{f}$ \\
\hline$p$ value & $<0.0001$ & $<0.0001$ & $<0.0001$ & $<0.0001$ & $<0.0001$ & $<0.0001$ & $<0.0001$ & $<0.0001$ & $<0.0001$ \\
\hline
\end{tabular}

${ }^{a} \mathrm{RDI}$ treatments: $100 \% \mathrm{ET}_{\mathrm{c}}, 70 \% \mathrm{ET}_{\mathrm{c}}$, and $25 \% \mathrm{ET}_{\mathrm{c}}$ represent replenishment of $100 \%, 70 \%$, and $25 \%$, respectively, of full-vine $\mathrm{ET}_{\mathrm{c}}$ from fruit set through harvest; $25 / 100 \% \mathrm{ET}_{\mathrm{c}}$ represents $25 \% \mathrm{ET}_{\mathrm{c}}$ from fruit set to veraison followed by $100 \% \mathrm{ET}_{\mathrm{c}}$ from veraison to harvest. SC treatments: control (10 days skin contact); EM: extended maceration (30 days skin contact).

bWithin a column, values followed by the same letter are not significantly different according to Fisher's LSD test at $p<0.05$. Evaluations made along a $15 \mathrm{~cm}$ unstructured line scale. 
It has been previously shown that extended maceration for 30 days or more increased astringency ratings by $22 \%$ in Cabernet Sauvignon (Scudamore-Smith et al. 1990) and by 34\% in Merlot (Casassa et al. 2013a). Similarly, in the present study, astringency ratings were, on average, 25\% higher in EM wines relative to the control wines (Table 5).

Bitterness perception was also affected by extended maceration. Although previous reports of the effects of extended maceration on bitterness perception are not conclusive (Yokotsuka et al. 2000, Casassa et al. 2013a), the present work has shown an average increase of $26 \%$ in the bitterness ratings of EM wines relative to those of the control wines (Table 5). This increase can also be further corroborated by inspection of the relative position of the ellipses for the EM wines and the loadings for bitterness in the PCA analysis. Monomeric flavan-3-ols content was generally higher in EM wines (Table 4). Because catechin and epicatechin are known to primarily elicit bitterness (Lesschaeve and Noble 2005), higher amounts of these monomers in EM wines may explain the observed higher bitterness ratings. In addition, there is a potential cooperative contribution to overall perceived bitterness perception by the judges from the oligomeric and protein-precipitable tannin content in EM wines (Table 4), but this hypothesis merits further research.

The PCA sensory loadings on the negative side of dimension 1 (Figure 1B) strongly associated the control wines with the purple component and saturation visual descriptors and the black and red fruit aroma descriptors. Overall CIELab chromatic differences between any given control and EM wines were detected at day 250 (Table 2), and these differences favored the control wines. These results suggest that purple component and saturation were the two color components directly related to higher perceived color in the control wines.

Comparatively higher ratings for fruit aroma attributes in the control wines (or lower ratings of both fruit aroma components in EM wines) (Table 5) can be attributed (but may not be limited) either to a genuine increase in the headspace concentration of these two aroma attributes in the control wines or to a masking effect resulting from the oxidized character in EM wines. Many compounds, including heptenal, methional, and phenylacetaldehyde, have been associated with the perception of oxidation in red wines (San Juan et al. 2012). However, in the context of the present study, acetaldehyde formation by metal-catalyzed oxidation of ethanol during extended maceration seems more plausible (Danilewicz 2003). Acetaldehyde at levels above its detection threshold bears a negative sensory connotation, and this compound was used as a standard for the oxidized character during the training of the sensory panel (Table 1). Furthermore, quinones resulting from the coupled oxidation of polyphenols can readily bind nucleophiles such as mercaptans and thiols bearing fruity notes (Nikolantonaki et al. 2010), thus lowering perceived fruitiness. However, the generation of an oxidized character and a decrease in the fruit aroma of the wine may not necessarily be a causative result of the application of extended maceration, as other studies have found no significant increases of the oxidative character upon extended maceration (Casassa et al. 2013a) or no effect of it in the wine's fruit flavor (Harbertson et al. 2009). In the present study, the oxidized character did develop after the extended maceration, although the ratings for the oxidized character in these wines averaged $3 \mathrm{~cm}$ on the $15 \mathrm{~cm}$ unstructured scale (Table 5), which is in the low perception range of the scale. However low this oxidative character, it was enough to reduce the ratings of red and black fruit in the EM wines by $26 \%$ and $21 \%$, respectively, relative to the control wines.

The sensory impact of the RDI treatment was a function of dimension 2 , which explained $17 \%$ of the residual variability of dimension 1 . Wines from the $100 \% \mathrm{ET}_{\mathrm{c}}$ treatment clustered at the lower end of dimension 2 (Figure 1A), indicating the lowest perception for color, fruity aromas, and mouthfeel attributes. The $100 \% \mathrm{ET}_{\mathrm{c}}$ treatment was included in the experimental design to explore the relationship between the application of an irrigation protocol based on replenishment of the full evapotranspirative demand and the generation of vegetative aromas in the resulting wines under the premise that a more vigorous canopy would lead to an enhancement of vegetative aromas (Allen and Lacey 1993). However, the vegetal component was confirmed to be absent in the $100 \% \mathrm{ET}_{\mathrm{c}}$ wines (and in all the wines) and thus was not selected as a discrimination term during the panel evaluations. This result suggests that, under some combinations of cultivar, clone, climate, and soil, supplying the full evaporative demand does not necessarily lead to vegetative flavors in the resulting wines.

The wines of the 70\% $\mathrm{ET}_{\mathrm{c}}$ and $25 / 100 \% \mathrm{ET}_{\mathrm{c}}$ treatments were distributed in the medial region of dimension 2 defined by the aromatic descriptors red and black fruit aroma (control wines) and the chromatic descriptors red and brown component (EM wines) (Figure 1). Although not necessarily causative, the application of different RDI protocols have been linked to enhanced concentration of fruity norisoprenoids in the resulting wines (Qian et al. 2009, Ou et al. 2010). The interconversion of carotenoids to odorant $\mathrm{C}_{13}$-norisoprenoids has yet to be conclusively established, but it is believed that reduced vine vigor may result in increased sun exposure and berry temperature in the fruiting zone, thereby leading to carotenoid degradation with the concomitant increase in $\mathrm{C}_{13^{-}}$norisoprenoids precursors (Kondouras et al. 2006, Bindon et al. 2007). While we did not identify these compounds analytically, the generalized trend for the sensory results presented here is consistent with these previous studies. Finally, the $25 \% \mathrm{ET}_{\mathrm{c}}$ treatment generated wines with higher purple component and saturation in the control wines, consistent with comparatively higher content of anthocyanins and small polymeric pigments in these wines (Table 3 ). When the $25 \%$ $\mathrm{ET}_{\mathrm{c}}$ treatment was processed with EM, the sensory profile shifted toward a pronounced oxidized character, bitterness, and astringency.

Also of significance was the overlap of the $70 \% \mathrm{ET}_{\mathrm{c}}$ control and $25 / 100 \% \mathrm{ET}_{\mathrm{c}}$ control wines on the left side of dimension 1 (Figure 1A). The ellipses represent empirical descriptions of the variability of the sensory evaluations (Husson et al. 2005), and if the ellipses are superimposed, then the wines are not significantly different from a sensory standpoint. Conversely, 

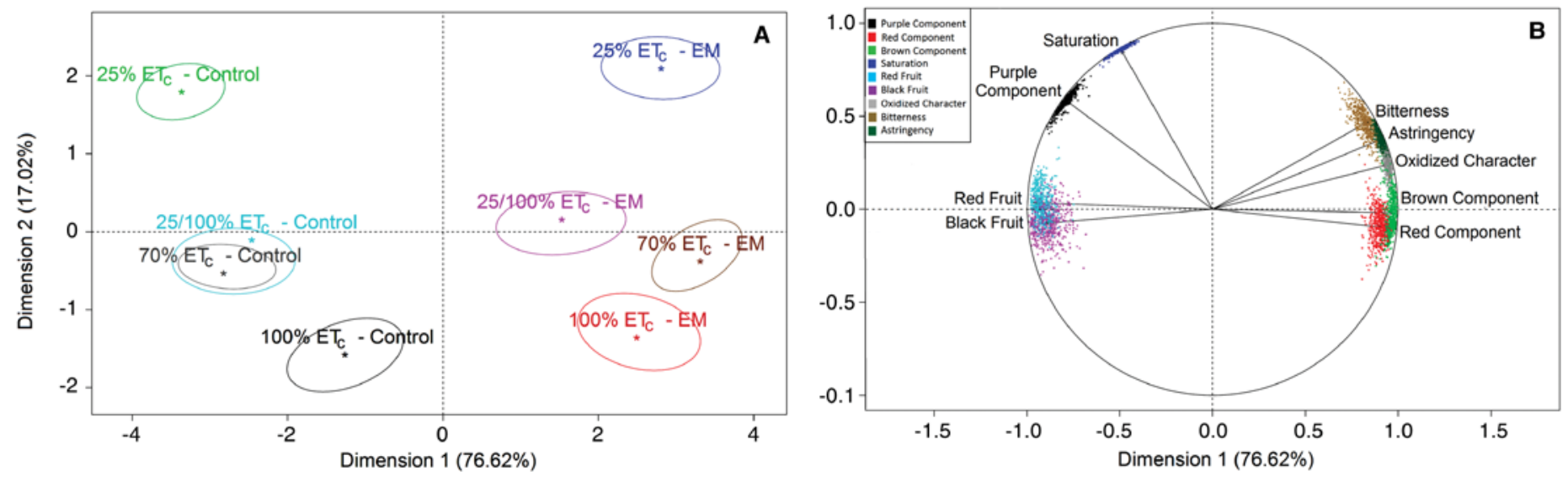

Figure 1 Principal component analysis of descriptive sensory data of Cabernet Sauvignon wines evaluated by a trained panel $(n=15)$ : $($ A) confidence ellipses based on multivariate distribution of Hotelling's test for $p<0.05$ indicating $95 \%$ confidence intervals and (B) sensory loadings. RDI treatments: $100 \% \mathrm{ET}_{c}, 70 \% \mathrm{ET}_{c}$, and $25 \% \mathrm{ET}_{\mathrm{c}}$ represent replenishment of $100 \%, 70 \%$, and $25 \%$, respectively, of full-vine $\mathrm{ET}_{\mathrm{c}}$ from fruit set through harvest; $25 / 100 \% \mathrm{ET}_{\mathrm{c}}$ represents $25 \% \mathrm{ET}_{\mathrm{c}}$ from fruit set to veraison followed by $100 \% \mathrm{ET}_{\mathrm{c}}$ from veraison to harvest. Winemaking treatments: $\mathrm{C}$, control (10 days skin contact); EM, extended maceration (30 days skin contact).
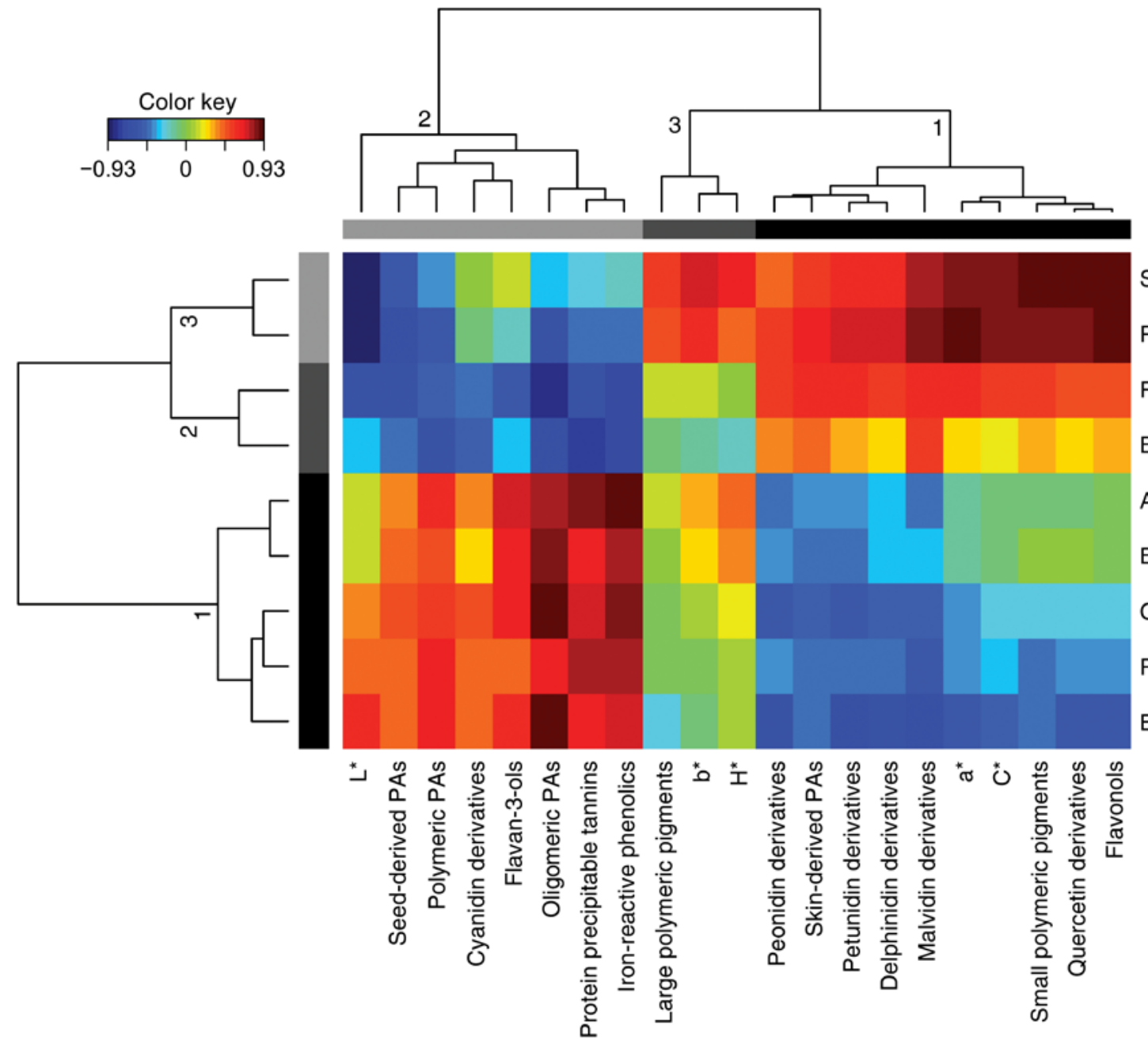

Saturation

Purple component

Red fruit aroma

Black fruit aroma

Astringency

Bitterness

Oxidized character

Red component

Brown component

\section{Chemical analysis}

Figure 2 Canonical correlation analysis showing clustered image maps of the correlation between significant sensory and chemical attributes considering all wines $(n=16)$ in the experiment. The dark red and blue colors indicate positive and negative correlation coefficient values, respectively, whereas light green colors indicate near zero correlation coefficient values. Cluster membership within sensory and chemical data is indicated as different shades of grey and black. $L^{*}$ : lightness; PAs: proanthocyanidins; $b^{*}$ : yellow component; $H^{*}$ : hue; $a^{*}$ : red component; $C^{*}$ : saturation. 
the general absence of overlap in six out of the eight treatments highlights the magnitude of the sensory differences. Furthermore, the compression of the ellipses is an indication of the reliability of the panel data.

Correlation between chemical and sensory data. The relationship between the significant chemical features of the wines and their sensory properties was examined by canonical correlation analysis (Figure 2). In addition to an agglomerative hierarchical cluster analysis of the chemical and sensory data sets, the correlation coefficients between any given pair of variables in the two retained dimensions are also provided (González et al. 2012). Shared cluster membership indicates the strength of the relationship between the canonical variates for both the chemical and sensory variables. For the chemical and sensory data sets, the cluster containing the highest number of variables was labeled cluster 1 , the cluster with the next highest number of variables was labeled cluster 2 , and so forth. For the chemical analyses, cluster 1 was composed of all the anthocyanin derivatives (except cyanidin), skin-derived proanthocyanidins, total flavonols, quercetin derivatives, small polymeric pigments, the red CIELab component $\left(\mathrm{a}^{*}\right)$, and saturation $\left(\mathrm{C}^{*}\right)$. Cluster 2 was composed of flavan-3-ols, oligomeric and polymeric proanthocyanidins, seed-derived proanthocyanidins, protein precipitable tannins, iron reactive phenolics, lightness $\left(\mathrm{L}^{*}\right)$, and cyanidin derivatives. Cluster 3 was composed of large polymeric pigments, the yellow CIELab component $\left(b^{*}\right)$, and the hue angle $\left(\mathrm{H}^{*}\right)$. For the sensory data set, three main clusters were identified. Cluster 1 was composed of astringency, bitterness, oxidized character, and red and brown color components. Cluster 2 was composed of red and black fruit aromas, whereas cluster 3 consisted of saturation and purple component. To understand which chemical variables were positively or negatively correlated with the sensory variables, the cluster image map provides the observed correlation coefficient values between any pair of variables. Positive correlation coefficients close to 0.93 were observed between protein precipitable tannins, iron-reactive phenolics, and oligomeric proanthocyanidins as well as astringency, bitterness, and brown component. These sensory attributes defined the sensory profile of extended maceration wines, thus suggesting that for the wines analyzed here, bitterness and astringency are highly correlated with the content of oligomeric proanthocyanidins (mean degree of polymerization up to 5 flavan-3-ols subunits) and also with protein-precipitable tannins, seed-derived proanthocyanidins, and overall phenolic concentration. Likewise, positive correlation coefficients were observed between the color sensory attributes saturation and purple component and the chemical attributes flavonols, quercetin derivatives, small polymeric pigments, $a^{*}, C^{*}$, and malvidin and delphinidin derivatives. As control wines were chromatically (Table 2) and sensorially (Table 5) more colored than EM wines, the aforementioned chemical variables may most likely be responsible for the perceived color features of control wines. In particular, a positive correlation between small polymeric pigments, $\mathrm{C}^{*}$, and monomeric anthocyanins has been previously reported in Merlot wines obtained after 10 days of skin contact (Casassa et al. 2013a), consistent with the results reported here. Positive correlations were also observed between flavan-3-ol content and the perception of both astringency and bitterness, suggesting that at the concentration of these monomers in EM wines (overall mean: $346 \pm 37$ $\mathrm{mg} / \mathrm{L}, \mathrm{n}=8$ ), the perception of both bitterness and astringency could be at least partially explained by the simultaneous occurrence of a comparatively higher concentration of flavan-3-ols and oligomeric proanthocyanidins. Nevertheless, since astringency and bitterness were also correlated with multiple phenolic measures (e.g., oligomeric proanthocyanidins, protein-precipitable tannins, iron-reactive phenolics), the occurrence of a single causative effect for both sensory features is unlikely.

\section{Conclusions}

The sensory effects of extended maceration and four different RDI treatments and some of their interactive effects were studied under winemaking conditions comparable with those of a commercial scale. While the application of the different RDI treatments primarily produced differences in color, astringency, and bitterness in the resulting wines, the effect of the two contrasting maceration treatments affected all sensory attributes. Thus, under our experimental conditions, the maceration treatments had a comparatively higher impact than the RDI treatments in the sensory and chemical profile of the wines.

Chromatic attributes were significantly enhanced in the $25 \% \mathrm{ET}_{\mathrm{c}}$ control treatment and were also highly correlated with the flavonol and anthocyanin derivatives content and small polymeric pigments. Red and black fruit aroma attributes were favored in the controls of the $70 \% \mathrm{ET}_{\mathrm{c}}$ and $25 / 100 \% \mathrm{ET}_{\mathrm{c}}$ treatments. These results suggest that moderate $\mathrm{RDI}$ protocols such as $70 \% \mathrm{ET}_{\mathrm{c}}$ and $25 / 100 \% \mathrm{ET}_{\mathrm{c}}$ positively impact the fruity component of wine aroma, possibly by favoring accumulation of norisoprenoids, whereas more severe RDI protocols such as $25 \% \mathrm{ET}_{\mathrm{c}}$ increased perceived color saturation, astringency, and bitterness. Extended maceration resulted in wines with comparatively lower fruit-based aromas and perceived wine color saturation, but enhanced the perception of bitterness and astringency, with the latter possibly arising from the concurrent effect of a high concentration of flavan-3-ols and oligomeric proanthocyanidins in these wines. Thus, extended maceration for 30 days or more appears to have limited merit as a winemaking practice. If wines with high tannin content are sought for stylistic or blending purposes, then practices such as prefermentation runoff (saignée) may be a more rational option in light of optimizing winery logistics.

\section{Literature Cited}

Allen, M.S., and M.J. Lacey. 1993. Methoxypyrazine grape flavour: Influence of climate, cultivar, and viticulture. Wein-Wissen. 48:211-213.

Baxter, N.J., T.H. Lilley, E. Haslam, and M.P. Williamson 1997. Multiple interactions between polyphenols and a salivary proline-rich protein repeat result in complexation and precipitation. Biochemistry 36:5566-5577. 
Bindon, K.A., P.R. Dry, and B.R. Loveys. 2007. Influence of plant water status on the production of $\mathrm{C}_{13}$-norisoprenoid precursors in Vitis vinifera L. cv. Cabernet Sauvignon grape berries. J. Agric. Food Chem. 55:4493-4500.

Boulton, R. 2001. The copigmentation of anthocyanins and its role in the color of red wine: A critical review. Am. J. Enol. Vitic. 52:67-87.

Callejón, R.M., B. Margulies, G.D. Hirson, and S.E. Ebeler. 2012. Dynamic changes in volatile compounds during fermentation of Cabernet Sauvignon grapes with and without skins. Am. J. Enol. Vitic. 63:301-312.

Casassa, L.F., C.W. Beaver, M.S. Mireles, and J.F. Harbertson. 2013a. Effect of extended maceration and ethanol concentration on the extraction and evolution of phenolics, color components and sensory attributes of Merlot wines. Aust. J. Grape Wine Res.19:25-39.

Casassa, L.F., R.C. Larsen, C.W. Beaver, M.S. Mireles, M. Keller, W.R. Riley, R. Smithyman, and J.F. Harbertson. 2013b. Impact of extended maceration and regulated deficit irrigation (RDI) in Cabernet Sauvignon wines. Characterization of proanthocyanidin distribution, anthocyanin extraction and chromatic properties. J. Agric. Food Chem. 61:6446-6457.

Chapman, D.M., G. Roby, S.E. Ebeler, J.X. Guinard, and M.A. Matthews. 2005. Sensory attributes of Cabernet Sauvignon wines made from vines with different water status. Aust. J. Grape Wine Res. $11: 339-347$

Danilewicz, J.C. 2003. Review of reaction mechanisms of oxygen and proposed intermediate reduction products in wine: Central role of iron and copper. Am. J. Enol. Vitic. 54:73-85.

Gawel, R., A. Oberholster, and I.L. Francis. 2000. A mouth-feel wheel: Terminology for communicating the mouth-feel properties of red wine. Aust. J. Grape Wine Res. 6:203-207.

González, I., K.A. Lê Cao, M.J. Davis, and S. Déjean. 2012. Visualising associations between paired 'omics' data sets. BioData Min. 5:19.

Harbertson, J.F., E.A. Picciotto, and D.O. Adams. 2003. Measurement of polymeric pigments in grape berry extracts and wines using a protein precipitation assay combined with bisulfite bleaching. Am. J. Enol. Vitic. 54:301-306.

Harbertson, J.F., M.S. Mireles, E.D. Harwood, K.M. Weller, and C.F. Ross. 2009. Chemical and sensory effects of saignée, water addition, and extended maceration on high Brix must. Am. J. Enol. Vitic. 60:450-460.

Husson, F., S. Lê, and J. Pagès. 2005. Confidence ellipses for the sensory profile obtained by principal component analysis. Food Qual. Prefer. 16:245-250.

ISO. 1977. ISO 3591. Sensory Analysis-Apparatus: Wine Tasting Glass. International Organization for Standardization, Geneva.

Koundouras, S., V. Marinos, A. Gkoulioti, Y. Kotseridis, and C. van Leeuwen. 2006. Influence of vineyard location and vine water status on fruit maturation of nonirrigated cv. Agiorgitiko (Vitis vinifera L.). Effects on wine phenolic and aroma components. J. Agric. Food Chem. 54:5077-5086.

Lawless, H.T., and H. Heymann. 2010. Sensory Evaluation of Food. Springer, New York.

Lesschaeve, I., and A.C. Noble. 2005. Polyphenols: Factors influencing their sensory properties and their effects on food and beverage preferences. Am. J. Clin. Nutr. 81:330S-335S.

Mehansho, H., L.G. Butler, and D.M. Carlson. 1987. Dietary tannins and salivary proline-rich proteins: Interactions, induction and defense mechanisms. Ann. Rev. Nutr. 7:423-440.
Nikolantonaki, M., I. Chichuc, P.L.Teissedre, and P. Darriet. 2010. Reactivity of volatile thiols with polyphenols in a wine-model medium: Impact of oxygen, iron, and sulfur dioxide. Anal. Chim. Acta 660:102-109.

Ou, C., X. Du, K. Shellie, C. Ross, and M.C. Qian. 2010. Volatile compounds and sensory attributes of wine from cv. Merlot (Vitis vinifera L.) grown under differential levels of water deficit with or without a kaolin-based, foliar reflectant particle film. J. Agric. Food Chem. 58:12890-12898.

Pickering, G.J., K. Simunkova, and D. DiBattista. 2004. Intensity of taste and astringency sensations elicited by red wines is associated with sensitivity to PROP (6- $n$-propylthiouracil). Food Qual. Pref. 15:147-154.

Pineau, B., J.C. Barbe, C. van Leeuwen, and D. Dubourdieu. 2007. Which impact for $\beta$-damascenone on red wines aroma? J. Agric. Food Chem. 55:4103-4108.

Poncet-Legrand, C., A. Edelmann, J.L.Putaux, D. Cartalade, P. SarniManchado, and A. Vernhet. 2006. Poly(L-proline) interactions with flavan-3-ols units: Influence of the molecular structure and the polyphenol/protein ratio. Food Hydrocolloids 20:687-697.

Poncet-Legrand, C., C. Gautier, V. Cheynier, and A. Imberty. 2007. Interactions between flavan-3-ols and poly(L-proline) studied by isothermal titration calorimetry: Effect of the tannin structure. J. Agric. Food Chem. 55:9235-9240.

Preys, S., G. Mazerolles, P. Courcoux, A. Samson, U. Fischer, M. Hanafi, D. Bertrand, and V. Cheynier. 2006. Relationship between polyphenolic composition and some sensory properties in red wines using multiway analyses. Anal. Chim. Acta 563:126-136.

Qian, M.C., Y. Fang, and K. Shellie. 2009. Volatile composition of Merlot wine from different vine water status. J. Agric. Food Chem. 57:7459-7463

Sacchi, K.L., L.F. Bisson, and D.O. Adams. 2005. A review of the effect of winemaking techniques on phenolic extraction in red wines. Am. J. Enol. Vitic. 56:197-206.

San Juan, F., J. Cacho, V. Ferreira, and A. Escudero. 2012. Aroma chemical composition of red wines from different price categories and its relationship to quality. J. Agric. Food Chem. 60:5045-5056.

Scudamore-Smith, P.D., R.L. Hooper, and E.D. McLaran. 1990. Color and phenolic changes of Cabernet Sauvignon wine made by simultaneous yeast/bacterial fermentation and extended pomace contact. Am. J. Enol. Vitic. 41:57-67.

Simon, C., K. Barathieu, M. Laguerre, J. Schmitter, E. Fouquet, I. Pianet, and E.J. Dufourc. 2003. Three-dimensional structure and dynamics of wine tannin-saliva protein complexes. A multitechnique approach. Biochemistry 42:10385-10395.

Vidal, S., L. Francis, A.C. Noble, M. Kwiatkowski, V. Cheynier, and E.J. Waters. 2004. Taste and mouth-feel properties of different types of tannin-like polyphenolic compounds and anthocyanins in wine. Anal. Chim. Acta 513:57-65.

Weber, F., K. Greve, D. Durner, U. Fischer, and P. Winterhalter. 2013. Sensory and chemical characterization of phenolic polymers from red wine obtained by gel permeation chromatography. Am. J. Enol. Vitic. 64:15-25.

Yokotsuka, K., M. Sato, N. Ueno, and V.L. Singleton. 2000. Colour and sensory characteristics of Merlot red wines caused by prolonged pomace contact. J. Wine Res. 11:7-18. 